\title{
Case Report: A Rare Case of Tumor: A Metastatic GIST
}

\author{
Kalaji Manhal1* ${ }^{*}$, Terryn François Xavier ${ }^{1}$, Henry Paulina ${ }^{2}$, Petit Bénédicte ${ }^{3}$ and Mansvelt Baudouin ${ }^{1}$ \\ ${ }^{1}$ Unité de chirurgie digestive, Hôpital de Jolimont, Belgium \\ ${ }^{2}$ Service anatomo-pathologique, Hôpital de Jolimont, Belgium \\ ${ }^{3}$ Service d'oncologie, Hôpital de Jolimont, Belgium
}

Submission: August 14, 2019; Published: August 27, 2019

*Corresponding author: Kalaji Manhal, Unité de chirurgie digestive, Hôpital de Jolimont, Rue Louis Franson 2, 7100 Haine Saint-Pierre, Belgium

\begin{abstract}
Gastrointestinal Stromal Tumors "GIST" is a rare form of digestive tract cancer with an estimated incidence of 15 cases per million population with an average age of 60 years. The surgical methods remain the main form of treatment and the only curative one. This case study is about a 5-year-old patient who presented non-specific abdominal pain and impaired general state. The CT-scan showed a voluminous abdominal mass located in the stomach as well as two liver metastases. We decided to perform a surgical biopsy of the gastric mass in order to identify its type. The anatomopathological analysis concluded in a Gastrointestinal Stromal Tumor, probably of gastric origin. In this context, we decided to initiate an Imatinib treatment: $400 \mathrm{mg}$ a day per os in one take. The patient initially responded very well to the treatment with a decrease of the size of the gastric tumor but, after 4 years, the mass started to further increase in volume.
\end{abstract}

After multidisciplinary discussion and involvement of the patient, surgical resection was agreed upon. No lymph node resection was done since lymph node metastases are rare. We performed a total gastrectomy with complete monobloc surgical resection of the tumor as well as a metastasectomy of the two liver lesions, an ablation of lesion on the ligamentum teres hepatis and hepatic hilum and finally a preventive cholecystectomy

Keywords: GastroIntestinal Stromal Tumors (GIST); Imatinib, Surgery

Abbrevations: GIST: Gastro-Intestinal Stromal Tumor

\section{Introduction}

Although gastrointestinal stromal tumors (GIST) are the most frequent sarcomas, they have been very poorly studied up until twenty years ago [1].

These tumors are the most common mesenchymal tumors of the gastrointestinal tract but still represent less than $1 \%$ of all gastrointestinal tumors [2]. GIST is a group of mesenchymal tumors that derive from interstitial cells of Cajal and which develop from the Muscularis propria. They may be acquired or genetic [3].

Imatinib has revolutionized the management of locally advanced and metastatic GIST. However, the surgical methods remain the main form of treatment and the only curative one [4]. This case report presents a metastatic gastric gastrointestinal stromal tumor recently removed in a 65-year-old male patient, the outcome and a literature review of the pathological identification, sites of origin, prognosis and treatment.
Case

A 65-year-old male patient with no significant medical history other than type 2 diabetes consulting for non-specific abdominal pain associated with a $2 \mathrm{~kg}$ weight loss and an impaired general state, which wasn't investigated. Family history was noncontributory.

The abdomen was soft and painless during physical examination.

A contrast-enhanced thoraco-andominal CT-scan showed a voluminous abdominal mass measuring $25 \times 20 \mathrm{~cm}$ located in the stomach as well as two liver lesions. No pulmonary lesions were found. After a multidisciplinary discussion, we decided to proceed to a surgical biopsy of the gastric mass in order to identify the etiology. The anatomopathological analysis revealed a Gastrointestinal Stromal Tumor, probably of gastric origin. We decided to start a treatment with Imatinib (Glivec) 400mg [5]. 


\section{Juniper Online Journal of Case Studies}

The medical treatment with Imatinib worked well at first but a further increase in volume of the mass, but not the metastases, was discovered after four years. After a new multidisciplinary discussion, given the resectability of the lesion, it was decided to perform a surgical "en bloc" resection of the tumor [6].

\section{Discussion}

Until 1998, gastrointestinal stromal tumors remained largely unknown. In the beginning of the 80's, the generalization of immunohistochemistry techniques allowed us to take enabled a big step in the diagnosis, but also in the treatment of these tumors since they are characterized by a very frequent expression of KIT (CD117), whose expression is specific to the interstitial cells of
Cajal. GISTs are slightly more prevalent in male patients, with an average diagnosis age of 60 years $[7,8]$.

Our patient suffered from abdominal discomfort and abdominal bloating. After further questioning, he confirmed a feeling of early satiety. He denied any other symptoms.

If surgery is the standard procedure for all GIST of small intestine or rectum it is not the case for gastric GIST. The treatment strategy in these cases is affected by several factors: the size of the tumor, its location, its adhesions to nearby structures and presence or absence of metastasis [1,9] (Figure 1-7).

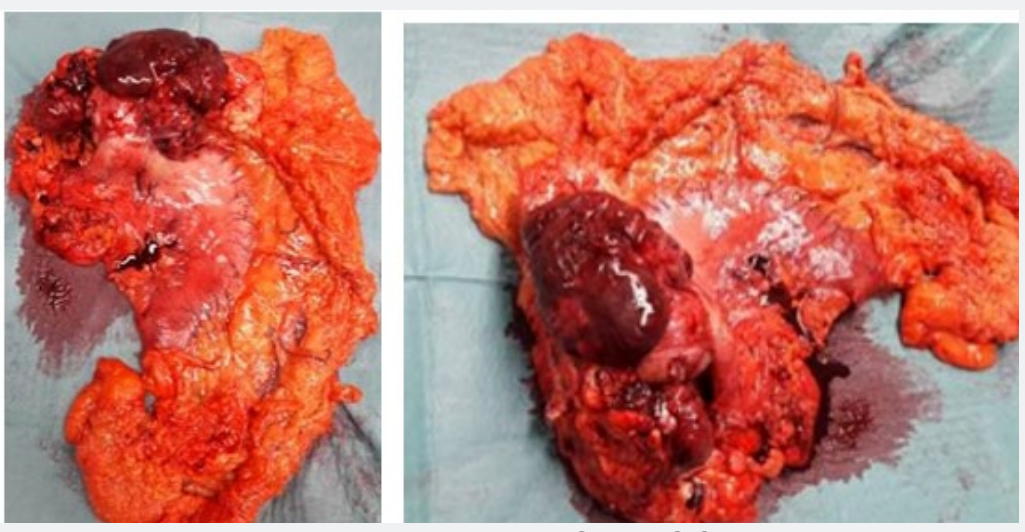

Figure 1: Macroscopic: Gastric GIST.

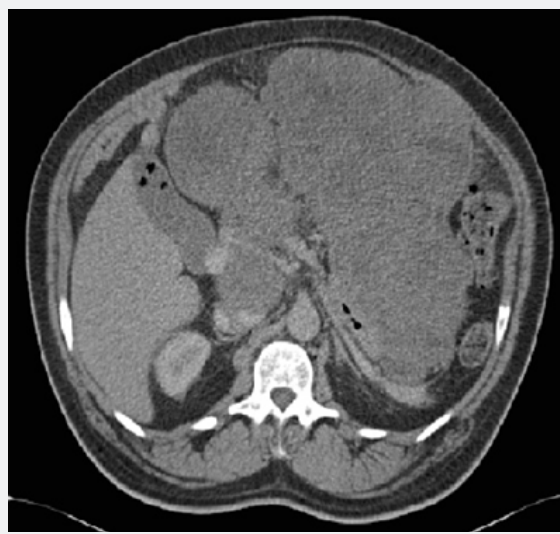

Figure 2: Voluminous heterogeneous mass exceeding $25 \mathrm{~cm}$ of diameter.

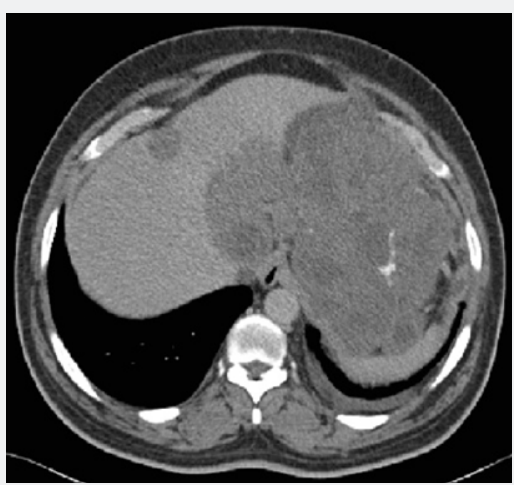

Figure 3: Hepatic lesion that correspond to a metastasis. 


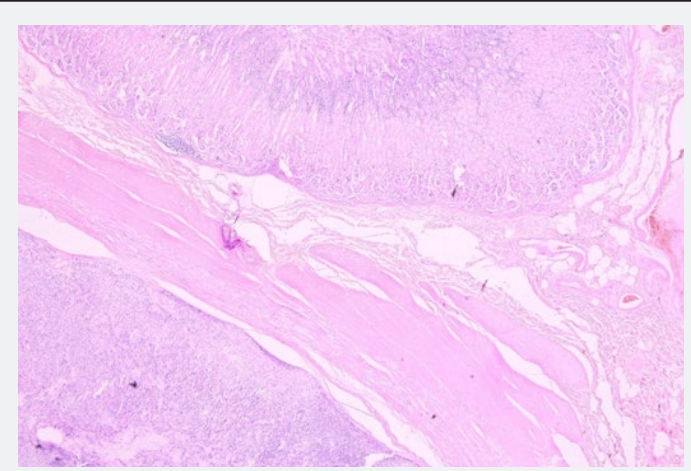

Figure 4: Localization in the depth of the gastric wall at the level of the muscularis propria.

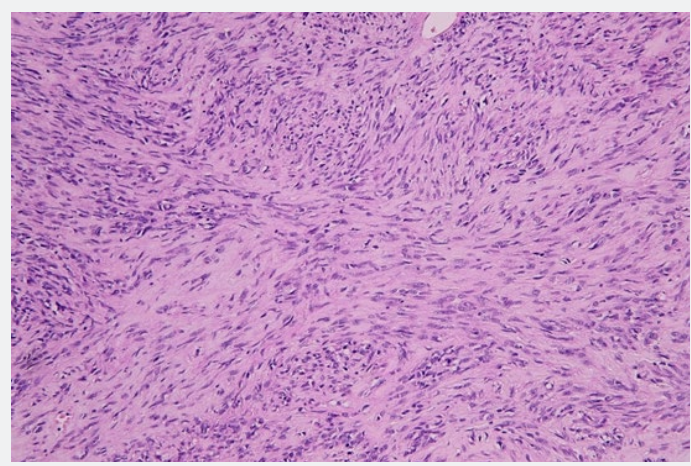

Figure 5: Fascicular structure with elongated fusiform cells. This is a feature of GISTs. Presence of some cellular atypia.

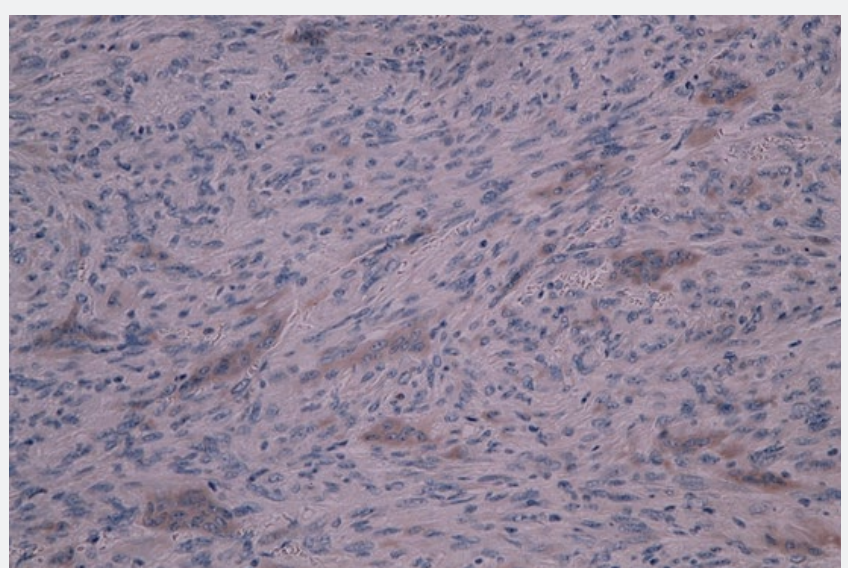

Figure 6: Immunolabelling (this analysis is essential to confirm the diagnostic of GIST): CKIT -CD117: positive with presence of brownish

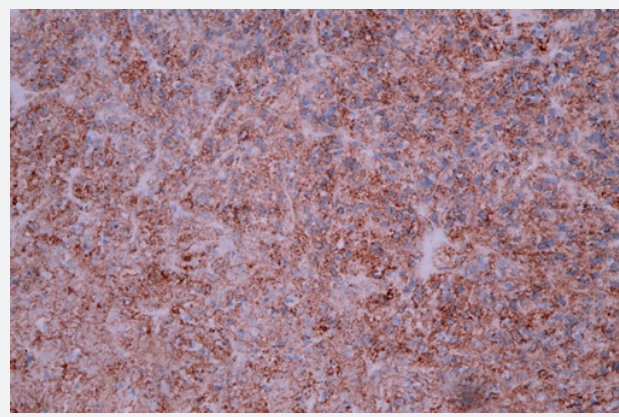

Figure 7: Immunolabeling of DOG 1: The expression of the protein "DOG1" is more specific than the expression "KIT" which can be observed in many other tumors. 
Some studies have suggested the high frequency of small gastric GIST ( $<10 \mathrm{~mm}$ in diameter) in adults after 50 years of age. The evolution of those tumors is not certain, and they could even regress in the future. Other studies seem to show that the risk of malignancy in GIST of the stomach is very low or inexistent when their diameter is smaller than $2 \mathrm{~cm}$ [10-12].

Thus, for gastric GISTs of less than $2 \mathrm{~cm}$, the choice between clinical surveillance and surgery will be based on symptoms (minor at this size), patients' general condition and location of the lesion in the stomach, facilitating resection or not. Endoscopic excision may be a treatment option for gastric GISTs of this size. Some Asian teams use this technique, which remains less invasive. It can also be combined with laparoscopy, but its efficiency remain uncertain. For non-metastatic gastric GIST greater than $2 \mathrm{~cm}$, complete surgical excision is the standard procedure with or without prior Imatinib treatment [13,14].

Our case is different from all these situations since it is a metastatic gastric GIST. The studies show that in responding or stable patients using Imatinib and potentially accessible for an $\mathrm{R} 0$ resection, the role of surgery remains to be clarified. Its feasibility has been shown, but its impact on survival hasn't yet been established. Two randomized trials (continuation of Imatinib versus surgery and continuation of Imatinib) were suspended due to slow recruitment. The Chinese trial, which included only 41 patients, did however show a non-significant trend in favor of the "surgery" group [15].

Our institution believes surgery remains the best solution and the only curative one if $\mathrm{R} 0$ is possible, even in metastatic cases [13]. We therefore proceeded to a total gastrectomy with complete monobloc surgical resection of the tumor as well as a metastasectomy of the two liver lesions, a removal of the ligamentum teres hepatis and hepatic hilum metastases and, finally, a preventive cholecystectomy. No lymphadenectomy was performed since lymph node metastases are rare, even in advances cases, and all the forty-eight lymph nodes associated to the surgical piece showed no anatomopathological signs of malignancy. At six months postoperatively, an abdominal contrast-enhanced CT scan showed no sign of resurgence.

\section{Conclusion}

Even though this is an isolated case, it might be worth thinking about the management of stable metastatic GIST under Imatinib. A new randomized study could, of course, allow a big step in the management of these tumors. Unfortunately, recruitment is a main limitation since these cases are rare.

\section{References}

1. Landi B, Blay JT, Bonvalot S, Brasseur M, Coindre JM, et al. (2018) Tumeurs stromales gastro-intestinales (GIST). Thésaurus National de Cancérologie Digestive.

2. Casali PG, Abecassis N, Bauer S, Biagini R, Bielack S, et al. (2018) Gastrointestinal stromal tumors : ESMO-EUROCAN clinical practice guidelines for diagnosis, treatment and follow-up. Ann Oncol 29(Suppl 4): iv68-iv78.

3. Nilsson B, Bümming P, Meis-Kindblom JM, Odén A, Dortok A, et al. (2005) Gastro-intestinal stromal tumors: the incidence, prevalence, clinical course, and prognostication in the pre-imatinib mesylate era-a population-based study in western Sweden. Cancer 103(4): 821-829.

4. Demetri GD, Wang Y, Wehrle E, Racine A, Nikolova Z, et al. (2009) Imatinib plasma levels are correlated with clinical benefit in patients with unresectable/metastatic gastrointestinal stromal tumors. J Clin Oncol 27(19): 3141-3147.

5. Van Oosterom AT, Judson I, Verweij J, Stroobants S, Donato di Paola E, et al. (2001) Safety and efficacy of imatinib 5STI571) in metastatic gastrointestinal stromal tumours: a phase I study. Lancet 358(9291): 1421-1423.

6. Russell S (2002) Gastrointestinal Stromal Tumors Treatment (PDQ®). National Cancer Institute. Health Professional Version.

7. Novelli M, Rossi S, Rodriguez-Justo M, Taniere P, Seddon B, et al. (2010) DOG1 and CD117 are the antibodies of choice in the diagnosis of gastro-intestinal stromal tumours. Histopathology 57(2): 259-270.

8. Rubin BP, Heinrich MC, Corless CL (2007) Gastrointestinal stromal tumour. The Lancet 369(9574): 1731-1741.

9. Demetri G, Benjamin R, Blanke CD, Choi H, Corless C, et al. (2004) Optimal management of patients with gastrointestinal stromal tumors (GIST): Expansion and update of NCCN Clinical Guidelines. J Natl Comp Cancer Network 2 Suppl 1: S-1-26.

10. Joensuu H (2006) Gastrointestinal stromal tumor (GIST). Ann Oncol 17(Suppl 10): x280-x286.

11. Taoufiq N, Naim A, Bouchbika Z, Benchekroune N, Jouhadi H, et al. (2017) Gastrointestinal Stromal Tumors «GIST »: status and news through our experience on 54 cases and review of literature. Pan Afr Med J 27: 165.

12. Bellamlih H, Bouimetarhan L, Amil T, En-nouali H, Chouaib N, et al. (2017) Rare digestive tumors: gastrointestinal stromal tumors (GIST): about a case of small bowel location and literature review. Pan Afr Med J 27: 274 .

13. Zalcberg JR, Verweij J, Casali PG, Le Cesne A, Reichardt P, et al. (2005) Outcome of patients with advanced gastro-intestinal stromal tumours crossing over to a daily imatinib dose of $800 \mathrm{mg}$ after progression on 400mg. Eur J Cancer 41(12): 1751-1757.

14. Gastrointestinal Stromal Tumor Meta-Analysis Group (MetaGIST) (2010) Comparison of two doses of imatinib for the treatment of unresectable or metastatic gastrointestinal stromal tumors: a metaanalysis of 1640 patients. J Clin Oncol 28(7): 1247-1253.

15. Du CY, Zhou Y, Song C, Wang YP, Wang YP, Jie ZG et al. (2014) Is there a role of surgery in patients with recurrent or metastatic gastrointestinal stromal tumours responding to imatinib: a prospective randomised trial in China. Eur J Cancer 50(10): 1772-1778. 
This work is licensed under Creative Commons Attribution 4.0 License DOI: 10.19080/JOJCS.2019.10.555789
Your next submission with Juniper Publishers will reach you the below assets

- Quality Editorial service

- Swift Peer Review

- Reprints availability

- E-prints Service

- Manuscript Podcast for convenient understanding

- Global attainment for your research

- Manuscript accessibility in different formats

( Pdf, E-pub, Full Text, Audio)

- Unceasing customer service

Track the below URL for one-step submission https://juniperpublishers.com/online-submission.php 